\title{
Correction to: Experimental study on the mechanical properties weakening mechanism of siltstone with different water content
}

\author{
Bingyang $\mathrm{Li}^{1,2} \cdot$ Jian Liu ${ }^{1,2} \cdot$ Kang Bian ${ }^{1,2} \cdot$ Fei $\mathrm{Ai}^{1,2} \cdot$ Xunjian $\mathrm{Hu}^{1,2} \cdot$ Ming Chen ${ }^{1,2} \cdot$ Zhenping Liu ${ }^{1,2}$ \\ Published online: 11 August 2020 \\ (C) Saudi Society for Geosciences 2020
}

Correction to: Arabian Journal of Geosciences (2019) 12: 656

https://doi.org/10.1007/s12517-019-4852-8

The original version of this paper was published with error. The second affiliation of the corresponding author should be "University of Chinese Academy of Sciences". Given in this article is the corrected affiliation.

The online version of the original article can be found at https://doi.org/ $10.1007 / \mathrm{s} 12517-019-4852-8$

Bingyang Li

liby0521@163.com

1 State Key Laboratory of Geomechanics and Geotechnical Engineering, Institute of Rock and Soil Mechanics, Chinese Academy of Sciences, Wuhan 430071, China

2 University of Chinese Academy of Sciences, Beijing 100049, China 